\title{
Are urban systems beneficial, detrimental, or indifferent for biological invasion?
}

\author{
Marc W. Cadotte $\cdot$ Simone Louise E. Yasui $\cdot$ Stuart Livingstone $\cdot$ \\ J. Scott MacIvor
}

Received: 3 April 2017 / Accepted: 14 August 2017/Published online: 19 October 2017

(C) Springer International Publishing AG 2017

\begin{abstract}
Urban environments are often seen as unique or degraded habitats that both present hardships for some sensitive species and provide opportunities to others. Non-indigenous species (NIS) are commonly referenced in the latter group, and are comprised of species that can tolerate the unique conditions or capitalize on the opportunities found in urban environments. Moreover, these urban beneficiaries may be those that normally cannot overcome competitive interactions in intact native communities, but find opportunity to flourish in urban habitats. We ask the question: do NIS benefit from urbanization? We answer this question using three strategies. First, we explore the problem conceptually, using community assembly theory. Second, we perform a broad
\end{abstract}

Guest Editors: Mirijam Gaertner, John R. U. Wilson, Marc W. Cadotte, J. Scott MacIvor, Rafael D. Zenni and David M. Richardson/Urban Invasions.

Electronic supplementary material The online version of this article (doi:10.1007/s10530-017-1586-y) contains supplementary material, which is available to authorized users.

M. W. Cadotte $(\bowtie) \cdot$ S. L. E. Yasui · J. S. MacIvor Department of Ecology and Evolutionary Biology, University of Toronto, 25 Willcocks St., Toronto, ON, Canada

e-mail: mcadotte@utsc.utoronto.ca

M. W. Cadotte $\cdot$ S. L. E. Yasui - S. Livingstone

J. S. MacIvor

Department of Biological Sciences, University of Toronto

Scarborough, 1265 Military Trail, Toronto, ON, Canada literature review. Finally, we analyze studies with sufficient information using a meta-analysis. We show that the available evidence supports the proposition that NIS benefit from urbanization, with NIS obtaining higher abundances and greater diversity in more urbanized habitats. There were only 43 studies that measured NIS abundance and diversity while adequately quantifying the degree of urbanization surrounding plots, and effect sizes (measured by Hedge's D) reveal that NIS obtain higher abundances in more urbanized habitats, and especially for invertebrates. Despite the intense interest in NIS dynamics and impacts, we note a general dearth of robust studies that adequately quantify 'urbanization', and we end with a general call for more detailed research.

Keywords Anthropogenic impacts · Community assembly $\cdot$ Invasion · Meta-analysis · Urban biodiversity $\cdot$ Urban ecology

S. L. E. Yasui

School of Earth, Environmental and Biological Sciences, Queensland University of Technology, 2 George St., Brisbane City, Australia

S. Livingstone

Department of Physical and Environmental Sciences, University of Toronto Scarborough, 1265 Military Trail, Toronto, ON, Canada 


\section{Introduction}

The invasion of non-indigenous species (NIS) into new regions has elicited concern from researchers and policy makers (Keller et al. 2014) because of perceived threats to agricultural productivity, native biodiversity and ecosystem functioning, and human aesthetics and wellbeing. Despite recent debates about the effects of invasive NIS on ecosystems and the importance of managing them (Davis et al. 2011b; Simberloff 2011), it is clear that NIS have both negative and positive impacts depending on the local context and the specific measure of impact (Pyšek et al. 2012). Negative impacts from invasive NIS include altering ecosystem functioning reducing the population sizes of other species, and causing local extinctions (Levine et al. 2003; Moles et al. 2012; Pyšek et al. 2017). However, there are also positive effects associated with the presence of NIS in some systems (Ewel and Putz 2004), including the use of non-native predators to control herbivores (Bertness and Coverdale 2013) and planting non-native plants to extend total flower duration for pollinators (Salisbury et al. 2015).

In urban habitats, a combination of altered environmental conditions and the loss or conversion of native habitat has resulted in the formation of a novel ecosystem type (Kowarik 2011). Given that intact ecosystems are believed to be relatively resistant to invasion by NIS (Cadotte and Lovett-Doust 2001; Moles et al. 2012), urban areas may offer unique opportunities for NIS species via three distinct causes. First, urban areas are defined by a unique combination of environmental conditions that do not exist in unmodified landscapes (Ricotta et al. 2009; Wilby and Perry 2006). Whether it be alterations to soil structure, hydrological regimes, nutrient dynamics or regional climate, organisms that persist in urban habitats need to be flexible or pre-adapted to these conditions.

The second reason why urban habitats are believed to offer opportunity for NIS success is because cities are islands of reduced competition (at least at some scales) or offer escape from natural enemies (Alberti 2015; Faeth et al. 2005). Many North American cities have experienced massive increases in small to medium sized mammals because of greater food availability and largely predator-free habitats (Bowers and Breland 1996; Gering and Blair 1999; Prange et al.
2003). Plants that should normally find themselves surrounded by a multitude of large-bodied competitors, can instead grow in urban habitats with fewer competitors. This is because very little light reaches the ground in natural communities, but in urban areas, most of the ground cover is open or low to the ground so that light reaches the soil surface, and thus we often see explosions in the abundances of weedy species with high specific leaf area that would normally be excluded from intact communities (Knapp et al. 2012). However, some locales within cities might experience high competition because suitable habitat is so limited.

The final reason for the opportunities NIS have in urban areas is immigration. Urban areas, by their very nature, are hotbeds of human activity. People frequently move goods among cities, and specifically import and introduce organisms for a variety of reasons. Thus, urban areas are the immigration beachheads for many NIS (Pyšek et al. 2010).

Given that there are reasons to suspect that urban areas provide disproportionate benefits to NIS, we assess the ecological mechanisms that could predict the success or failure of NIS in urbanized regions. We do this by developing the theoretical underpinnings of why urban areas might provide benefit for NIS in urban areas and then we assess the available evidence, in a qualitative review and a quantitative metaanalysis, to determine if NIS densities or population sizes and NIS richness do increase with urbanization. We further discuss whether NIS success in urban areas leads to increased negative impacts on native biodiversity and ecosystems.

Conceptual underpinning of NIS success in urbanized regions

Regardless of the exact way in which NIS and native species respond to urban environments, we need to understand the ecological dynamics of urban systems. The reason why we need theoretical underpinnings of NIS-urban relationships is to develop specific hypotheses about urban impacts on NIS and to move beyond simple correlations between urban variables and biodiversity (McDonnell and Hahs 2013). Urban environments result in novel ecological dynamics, patterns and processes (Alberti 2015; Faeth et al. 2005; Pickett et al. 2008; Williams et al. 2009), and here we focus specifically on community assembly (Fig. 1). What is critical for urban (non-human) organismal 
communities is how the urban environment selects for certain species out of a regional species pool (Fig. 1), which may contain species that would otherwise do well in a specific location if it was still in an unmodified state.

The question of how communities assemble and change over time has been under the microscope of ecological research for many decades (Connell and Slatyer 1977; Huston and Smith 1987; Pickett and McDonnell 1989). Communities are believed to be influenced by three distinct factors: (1) local site conditions-including local environmental conditions or history; (2) the availability or selection of species that could ostensibly colonize the local habitat; and (3) the performance of those species within the assemblage (Fig. 1) (Dickson and Foster 2008; Pickett and McDonnell 1989; Pickett et al. 2011; Williams et al. 2009). It is important to note that while it may be convenient to describe these factors as discrete processes, they actually interact in complex ways to shape local diversity patterns (Cadotte and Tucker 2017).

The local site conditions, including local climatic factors, resource availability, disturbance or contamination history, can have long-lasting effects on the types of species that can persist in a habitat. The local site conditions further influence the next two community assembly factors by determining species selection and performance. Local environmental conditions are believed to be integral to NIS success in new habitats and environmental matching between a species' native range and the new range is often the first step in assessing potential invasiveness of NIS (Peterson 2003; Pheloung et al. 1999). Further, species in their optimal climatic conditions are most likely to have an impact, via a number of different interactions but especially interspecific competition on other species (Brown 1984; Cadotte and Tucker 2017).

The second factor, species selection, determines which species may be able to persist at the local site (Fig. 1). This stage represents the interaction between the physical environment and species' traits. Urban systems are generally, though not universally, more stressful for many organisms, from the effects of noise and light on vertebrates to altered water regime effects on plants, which tend to select for species with drought-tolerant traits (Ariori 2014). There is some confusion about whether species filtered out are those that are absolutely unable to grow and reproduce in local environments (e.g., intrinsic rate of increase $<0$ ) or whether species' population growth rate is correlated with environmental gradients and that low, but

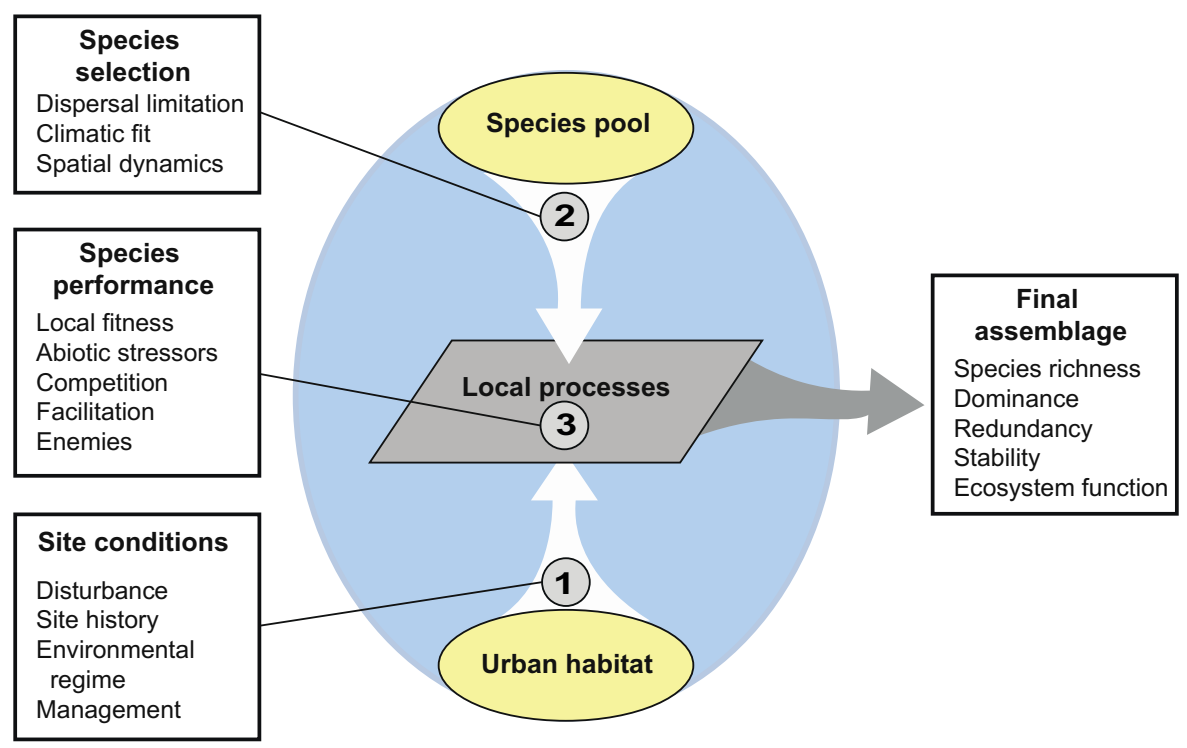

Fig. 1 A cartoon representation of basic ecological assembly mechanisms applied to the urban context. These assembly mechanisms determine which species can colonize a given area, their performance, the outcomes of species interactions, and the resulting diversity of the local community. In this framework, habitat diversity, composition and function represent the emergent outcome of selection from the regional species pool (\#1) and influences from local site conditions and anthropogenic activities (\#3) that both shape local processes and interactions (\#2) 
positive growth rates, in some locales, results in a species being unable to compete (Cadotte and Tucker 2017; Kraft et al. 2015) (Fig. 2). Regardless, the larger region contains a suite of species that could potentially colonize the local site (i.e., the species pool), as well, introducing species not currently found in the region can expand the species pool (Williams et al. 2009).

The final factor is species performance, and this broadly includes the outcomes of local species interactions (Fig. 1). This is the driver that is commonly studied in community ecology, especially examining species' competition for limited resources, and fundamental coexistence theories address this directly. Beyond simple matching of environmental conditions between species native and introduced ranges, the success of NIS in new habitats depends on both their reproductive success relative to other competitors and the degree of niche overlap (e.g., utilizing the same resources in the same way) (MacDougall et al. 2009; Shea and Chesson 2002). If a NIS has high niche overlap with a resident species, then competition will be intense and the species with higher average population growth rate will likely outcompete the other. Urban stresses can reduce growth rates if local conditions result in increased mortality or reduced birth rates.

How does community assembly in urban environments influence NIS?

It is not particularly helpful to think of native and NIS as discrete categories that are somehow fundamentally different in terms of their ecological needs and basic dynamics. That said, successful NIS tend to be a nonrandom subset of species that could potentially occur in a given locale (e.g., Ma et al. 2016). Thus, it is more helpful to start by focusing on broad ecological strategies of species before discussing NIS. The urban environment can provide strong selection for (or perhaps more appropriately, against) certain life history syndromes. A simplistic approach would be to focus on two types of species identified in Grime's tripartite classification (Grime 1974): those that are good competitors but sensitive to stress or disturbance, and those that are able to thrive in disturbed or stressful habitats but are not particularly competitive in benign conditions. We can identify two effects that reduce population growth rates when species are at low abundance (Chesson 2000), namely the effects of competition from locally dominant species $(f(c))$ and local environmental changes, stress, or disturbance that reduces growth and reproduction independent of the effects of competition $(f(s))$ (Fig. 2). Of course, we need to be cautious here because not all organisms will perceive the urban environment as disturbed or stressful, and so not all organisms will follow Grime's strict trade-off.

Due to these two effects $(f(c)$ and $f(s))$ on population growth, we expect that species that are less competitive will be more likely to find refuge in urbanized areas and perform better than in intact habitats where competition is high. Some native species maintain as high or higher densities in urban areas (Corlett 2006), such as Raccoons in eastern North America, but many

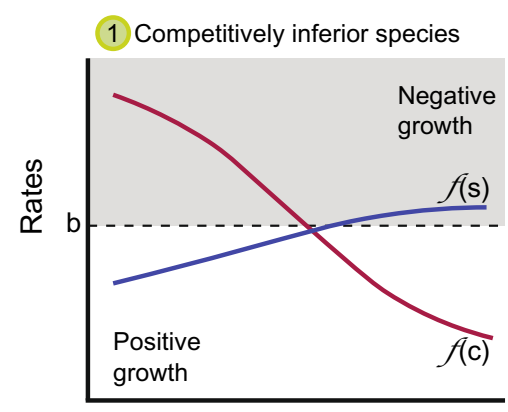

Urbanization gradient

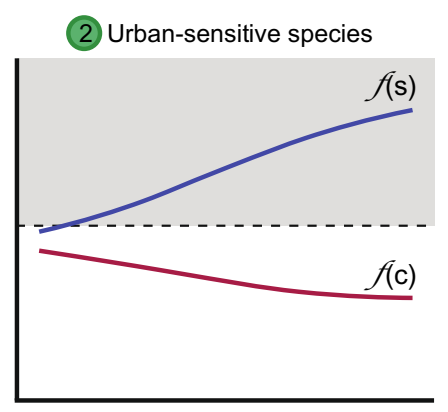

Urbanization gradient

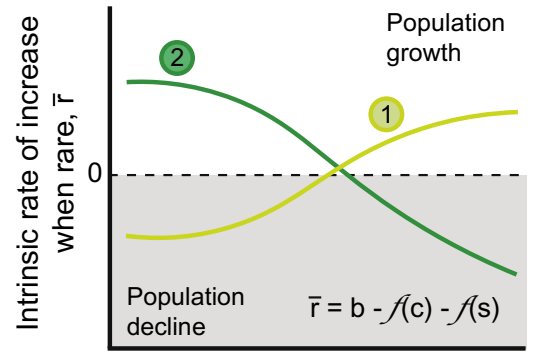

Urbanization gradient
Fig. 2 Population growth rates at low density $(\vec{r})$ should vary across urban gradients because of a combination of the responses to changes in competition (f(c)) and local environmental conditions $(\mathrm{f}(\mathrm{s}))$, which both reduce the potential population growth from pure recruitment (b). Given a tradeoff between $\mathrm{f}(\mathrm{c})$ and $\mathrm{f}(\mathrm{s})$, two types of species emerge: those that benefit from urbanization because the negative effects of competition (red lines) are greatly reduced, but are not greatly impacted by the negative environmental and disturbance effects (blue lines) experienced by more competitive species. These two groups of species (yellow and green, respectively) show opposing responses to urbanization 
others are adversely affected. Conversely, those species that are competitive but sensitive to the environmental effects of urbanization should reach larger population sizes outside of urban areas, in natural habitats. The performance and population sizes of species across urban gradients reflects their underlying ecology and the numbers of these species depends on the number of species in the regional species pool (or being introduced from elsewhere) that are competitively inferior or urban sensitive.

NIS that have successfully established within a region are more likely to be have strategies allowing them to deal with disturbance or the ephemeral and stressful conditions that might be found in urban areas, simply because of the colonization pathways (e.g., from other urban centers or agricultural areas) and the likelihood of openings for them to successfully establish in the first place (Cadotte and Lovett-Doust 2001). Conversely, the native biota from most regions contains a majority of species that rely on or occur in intact natural habitats. Thus, we should expect that a majority of native species perform less well than the NIS species in urbanized habitats (Fig. 3), simply because they represent a nonrandom subset of species with traits, behavioural or life-history strategies that allow these species to utilize disturbed or simplified conditions. Our naïve expectation should be that as we move across an rural-to-urban environmental gradient, there is a shift from relatively high native diversity to relatively high NIS diversity-though it is not clear how overall diversity should change across the gradient (Fig. 3), and depends on the relative sizes of the native and non-indigenous species pools. In a global analysis, Aronson et al. (2014) found that there tends to be more native bird and plant species than NIS in cities, simply because of the larger native species pools, but they also found that native diversity in cities was just a fraction of what would be found in intact habitats.

While we can expect that average population growth rates across all species will decrease (while recognizing substantial variation) across the urbanization gradient, it likely decreases more severely for natives because of the trade-off between competitive ability and strategies to deal with disturbance or stress (Fig. 3). It is important to recognize that competitive and other negative interactions are not only important in natural or undisturbed habitats, but are likely prominent in urban areas and disturbed habitats as well

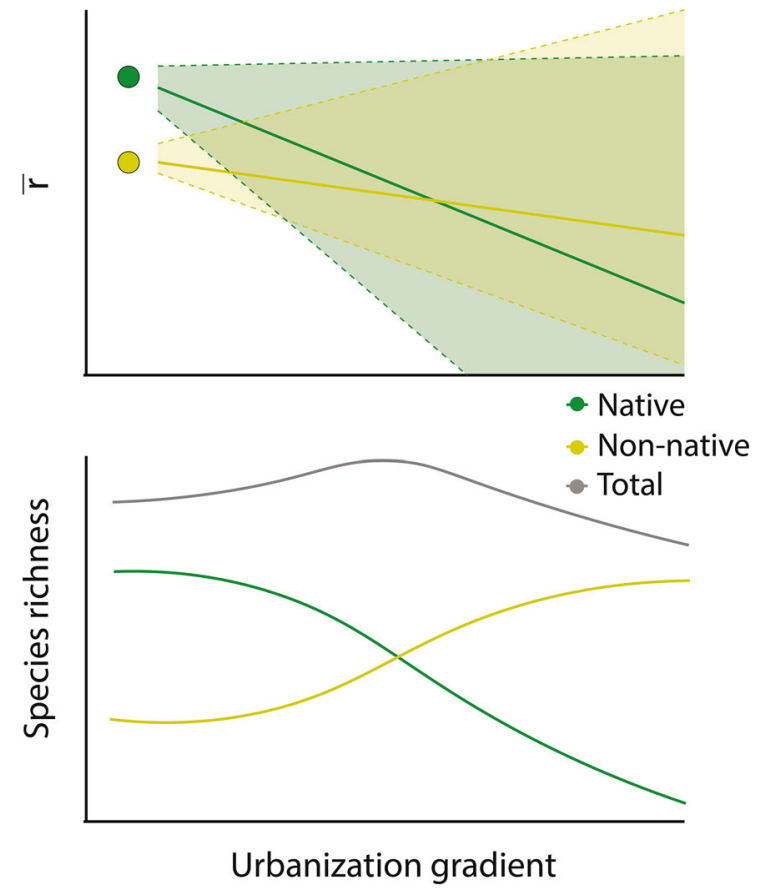

Fig. 3 A conceptual model of the impact on native and nonindigenous species (NIS) across an urban gradient (yellow and green, respectively). While it is difficult to make broad generalities about natives and NIS, because they are such heterogeneous groups, NIS, because of non-random selection and introduction pathways, are more likely to include species preadapted to deal with urban environmental stress and disturbance. Thus, on average, NIS fitness should be higher in urban habitats and the number of NIS increase across an urbanization gradient

(Chesson and Huntly 1997). Since native species and NIS might have unequal responses to an urbanization gradient, competitive advantage should shift to NIS in urban habitats (Fig. 4). This not only results from changes in reproduction and performance, but also because urban habitats might have less natural heterogeneity for species to exploit (Pickett et al. 2008) and so species' realized niches overlap much more than they would in natural habitats (Amarasekare 2003).

Once NIS are able to persist in urban environments, especially where competitively dominant species are limited, they may become invasive (see Box 1 for an example of an urban invasion; see also McLean et al. this issue). In this context, we define invasive as NIS that are able to establish populations and spread to new areas (Colautti and MacIsaac 2004). In order for NIS to become invasive they need to deal with a suite of 


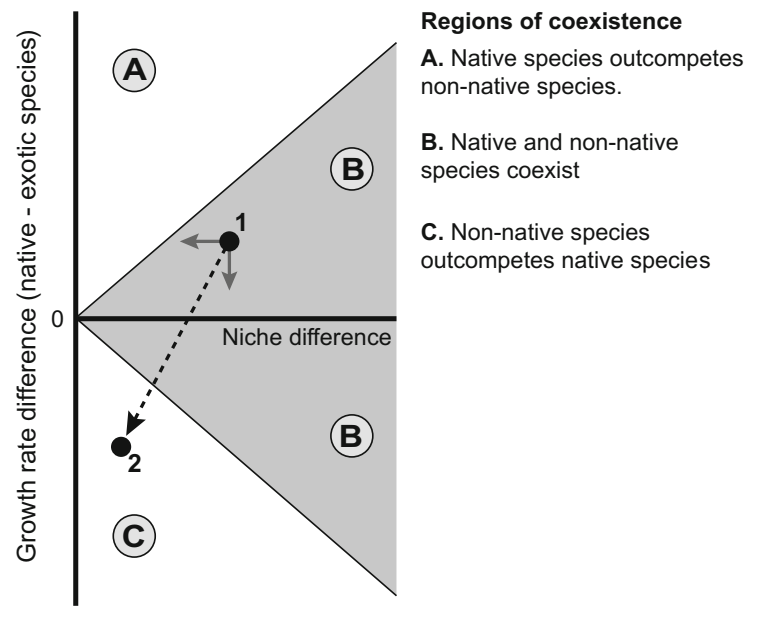

Fig. 4 The Chessonian representation of native-NIS competitive interactions (adapted from MacDougall et al. 2009), which is divided into three regions of competitive outcomes. Circle \#1 indicates a hypothetical scenario where native and NIS coexist in a natural habitat. With urbanization, native fitness and niche differences are reduced leading to competitive exclusion of the native (\#2)

biotic interactions beyond just competition, especially interactions with consumers and pathogens, as well as mutualists. Reductions in exploitative interactions increase reproductive rates and potentially expand realized niche space. However, the opposite will be true if mutualistic relationships are lost. Given that these types of interactions are likely influenced by urbanization, the question is: do urban environments increase NIS population sizes and NIS diversity? And finally, is there evidence that NIS invasion impacts on native biota are enhanced in urban habitats? To answer these questions, we perform both a review and metaanalysis of the available literature on urban invasions. The reason for both approaches is because we placed quite stringent criteria on the inclusion of studies into the meta-analysis, thus limiting the number of studies analyzed, and we wanted to incorporate general findings from studies that did not meet these criteria. As outlined in greater detail in the supplemental material, we searched Web of Science in May 2016 using the terms urban* AND Exotic AND Invasive, and we found 277 articles. For the meta-analysis, most papers were not included due to vaguely defined or quantified differences in urbanization (see below and the Supplemental Material). We did use many of these papers in the review section, which is augmented by other urban ecology or invasions reviews.
Review of NIS-urban relationships

At extremely large scales (e.g., nations, states, territories, etc.) NIS richness appears to be controlled by habitat area, biogeographical processes, and human activities (Allouche et al. 2012; Helmus et al. 2014; Lonsdale 1999). However, at small scales (i.e., at the habitat scale), NIS richness is controlled by the interaction of a number of complex factors (Fig. 1) including resident species diversity (Naeem et al. 2000), local contamination (Pyšek et al. 2003), and the presence of other NIS (Simberloff and Von Holle 1999). Urban centres appear to offer opportunities for disturbance-adapted species, which include numerous NIS, because these centres represent concentrations of economic and transportation activity, anthropogenic disturbance, unique environmental conditions, lower species diversity, and compromised ecological integrity (Chytrý et al. 2008; Lake and Leishman 2004; Pyšek et al. 2010).

From the conceptual framework laid out in the previous section, it is clear that a number of observations can be used to assess whether NIS benefit from urbanization, including estimates of reproductive success, diminished competitive interactions, increased population sizes, and species richness and diversity. All of these can be predicted to change across an urban gradient, with NIS more likely to benefit or at least be less impacted by urbanization compared to natives. Keeping definitions of success flexible allows us to assess a relatively heterogeneous literature.

A number of studies show that native species are likely to be negatively impacted by urbanization (Aronson et al. 2015). Native bird species have declined in urban areas, presumably because canopy and other resources are reduced compared to intact habitats (Soh et al. 2006). In urban streams in Los Angeles, USA, amphibians that are sensitive to water quality and habitat degradation decrease with increasing development, while stream occupancy by NIS increased (Riley et al. 2005). Further, native wetland plants have been observed to decline as urban human population density increases (Wei and Chow-Fraser 2006).

Of course, urbanization is not a singular axis to describe urban landscapes, and urban areas can be heterogeneous and human settlements could have been selected non-randomly with respect to native 
Box 1 Vincetoxicum rossicum, the extreme urban invader

The highly invasive exotic vine, Vincetoxicum rossicum, has become extremely abundant in both urban environments and remnants of native ecosystems within urban areas, throughout southern Ontario, Canada and northeastern United States (DiTommaso et al. 2005). Originally introduced in the late 1800's, there was a significant lag period before $V$. rossicum became a species of significant concern (Kricsfalusy and Miller 2008). It is now clear that invasion by $V$. rossicum is having a significant impact on local and regional biodiversity by suppressing the growth of native and non-invasive exotic plants. As one would expect, this has been shown to have negative impacts on the diversity of other trophic levels (Ernst and Cappuccino 2005). Several studies have examined potential mechanisms driving invasion by V. rossicum throughout these regions [e.g., enemy release (Milbrath 2008), propagule pressure and fitness (Ladd and Cappuccino 2005), broad environmental niche breadth (DiTommaso et al. 2005; Yasui 2016), associations with fungal generalists (Bongard et al. 2013), novel allelopathic compounds (Douglass et al. 2009), strong allee effect (Cappuccino 2004), a high degree of phenotypic plasticity (Yasui 2016), and toleration of low resources and significant local adaptation (Antunes and Sanderson 2013)]. Despite research showing that the vast majority of V. rossicum seeds fall relatively close to the parent plant (Ladd and Cappuccino 2005), occasional strong wind events can carry V. rossicum's feathery pappus-covered seeds significant distances leading to widespread invasion. Even with a low mean dispersal distance, the few individuals that disperse long distances have the strongest effect on the spread of a non-native (Caswell et al. 2003).

Similarly, seed dispersal in urban environments is facilitated by colonization along highway corridors where vehicles have been shown to enhance dispersal of invasive species (Von der Lippe and Kowarik 2007). V. rossicum has recently been added to the list of Noxious Weeds in Ontario, but land managers are struggling to control its spread due to its resilience and remarkable ability to colonize a wide range of habitats, both in the urban matrix and natural spaces (DiTommaso et al. 2005)

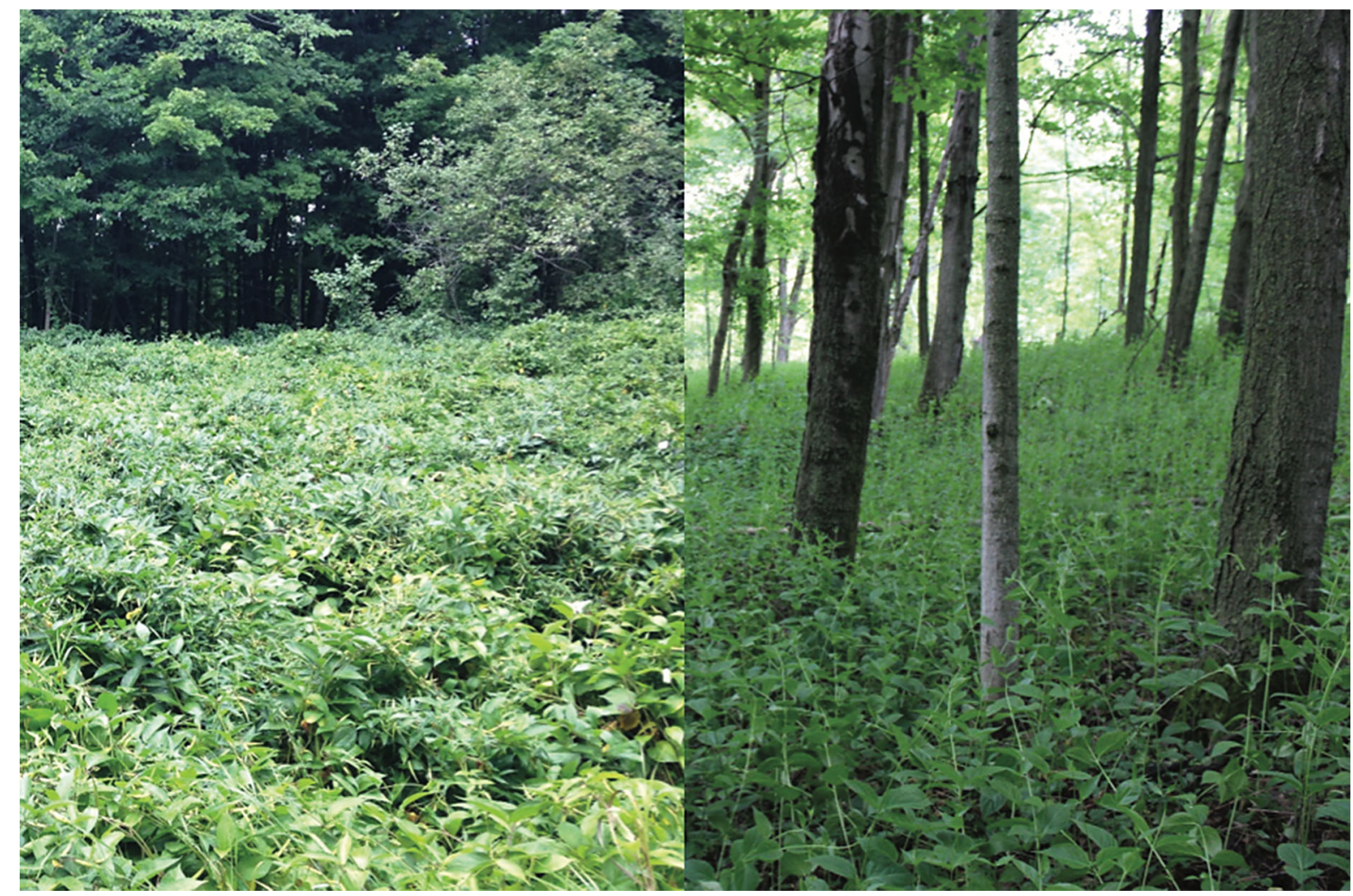

Examples of two habitats near Toronto, Canada completely dominated by $V$. rossicum. On the left is an example of a meadow overtaken by V. rossicum, and on the right is an invaded forest understory (photos by S. Livingstone)

diversity patterns. For example, high density urban areas in California have both higher numbers of rare native species and NIS (Schwartz et al. 2006).
Essentially, people tend to live in more attractive or biologically richer places that might harbour more diversity but urbanization also promotes NIS 
(Schwartz et al. 2006). Within urban areas, larger natural remnants enhance native diversity but they are also more invaded than natural areas outside of cities (Nielsen et al. 2014), likely as a result of surrounding landscape influences (Basnou et al. 2015; Golivets 2014; Ives et al. 2011; McCune and Vellend 2015; Wu et al. 2010). It has been shown that plant NIS richness increases with greater road network size and urban coverage (Gavier-Pizarro et al. 2010). These types of landscape variables highlight the importance of both dispersal pathways and habitat change for the success of ruderal NIS (Akasaka et al. 2015). Borgmann and Rodewald (2005) emphasize the role of habitat change in the invasion of woodlands by honeysuckle (Lonicera) species and showing that invasion was greater in more urbanized areas, which they attributed to disturbance. Human development also reduces small-scale habitat heterogeneity which reduces opportunities for species coexistence (Petren and Case 1998). For example, an invasive gecko was competitively superior over native geckos in human dominated landscapes in Hawaii because the invasive species can better capture insects in more homogeneous environments (such as smooth wall surfaces), even though species can coexist in more natural and complex habitats (Petren and Case 1998).

Several papers have reported that NIS richness increases with urbanization (Aronson et al. 2015; Blair and Johnson 2008; Chen et al. 2014). As is apparent in Fig. 1, species success and local diversity are influenced by a multitude of factors, and the literature identifies many potential causes for NIS success in urban areas. Broadly, these causes can be grouped into four classes:

1. Propagule pressure individuals or propagules of NIS are purposefully introduced into urban areas. Gardens and ponds, for example, are urban habitats where species are commonly introduced by individuals, government agencies, and private companies. For plants, it is well recognized that invasions can start from ornamental plantings (Lee et al. 2015), and for example, invasion in semi natural woodlands reflects residential proximity and planted non-native species richness (Sullivan et al. 2005). While education campaigns can promote the use of native species, there may be other priorities for homeowners. For example, in a survey of homeowners, the native status of trees was important, but not more than tree size and ease of maintenance (Pataki et al. 2013).

2. Reduced negative interactions Negative interactions like competition and predation are undoubtedly altered in urban habitats, but how they change might be context and taxa specific. For example, gardeners purposefully reduce species competition, and these gardens often harbour high NIS diversity (Smith et al. 2006). For some species, they may experience a release from predation or herbivory in urban areas, but the opposite could also be true. For example, introduced domestic cats are responsible for extremely high predation rates on songbirds in urban areas (Loyd et al. 2013).

3. Resource supply While urban areas can represent reduced resources for many species, including reduced nesting opportunities for waterfowl or spawning grounds for fish, some types of resources are greatly enhanced in urban areas. For example, pollination dependent exotic plants might have advantage in urban areas because of increased pollinator abundance and vice versa (Parker 1997). Exotic pollinators may also prefer exotic plants used in landscaping (MacIvor et al. 2015) or occurring spontaneously in cities (Barthell et al. 2001), increasing their foraging opportunities and competitive edge on native pollinators.

4. Altered environmental conditions Plant species diversity has decreased with urbanization in Harbin, China, but there has been an increase in tropical species as urban temperatures have increased (Chen et al. 2014). Further, intensively impacted anthropogenic sites (e.g., contaminated sites) are over-represented by NIS in cites and elsewhere (Pyšek et al. 2003). There is evidence that NIS are an ecologically narrower subset of the total flora; for example, they often come from fewer clades that are better adapted to the environmental conditions associated with human impacts (Ricotta et al. 2009)

In many cases these causes are actually difficult to separate into independent mechanisms (Box 1) since they all represent simultaneous effects of urbanization. For example, urban gardens are sites of purposeful introduction and thus increased propagule pressure, but maintained gardens represent a major alteration to 
the local environment and are further weeded to reduce the effects of interspecific competition. The point is that NIS seem to be the beneficiaries of urban development and we can ascribe causation to a relatively simple set of processes (Fig. 1).

NIS might do better in urban areas compared to native species, but what happens to total diversity across the urban gradient? The general conclusion is that NIS typically replace natives as systems become more urbanized. For example, total woody plant richness does not change across urban to rural gradient but the proportions of non-native and native do with more natives (less NIS) in rural settings (Aronson et al. 2015). There have been similar observations for birds, with suburban habitats having more species than natural woodlands because of native extinction and subsequent invasion (Blair and Johnson 2008), and the creation of artificial marine structures results in higher numbers of sessile NIS than on natural surfaces (Airoldi and Bulleri 2011). The change in total diversity depends then on the relative pool size for NIS and native species, and the life history strategies selected by anthropogenic environmental modifications. These pools are directly affected by human activities and preference. NIS vastly outnumber natives among planted urban trees, especially in hyperdiverse regions such as Brazil, which presumably have a large palette of native species to choose from (Moro and Castro 2015).

Meta-analysis of NIS diversity and performance across urban gradients

We conducted a literature search for studies that estimated NIS abundance and richness across urban gradients and used a meta-analysis to test two main hypotheses: (1) NIS abundance is greater in urban habitats; and (2) NIS richness is greater in urban habitats compared to less impacted habitats (see Supplemental material for details). Even though our search returned more than 200 articles (a number of which were used in the preceding review section), only 24 were used in the analysis because most studies did not adequately measure the degree of urbanization at specific locales (see the section title: 'Well designed studies are desperately needed' for further discussion of this issue), or did not provide the necessary summary statistics. Originally, we also considered measures of NIS impact across urbanization gradients, but we found only three studies adequately quantified impact (Cusack et al. 2015; Ferreira-Filho et al. 2015; Rodewald et al. 2015), and these were too heterogeneous in what they measured (e.g., impact on native species vs. impact on soil nutrients) to do a metaanalysis. Further, we were unable to analyze regression coefficients from continuous estimates of urbanization because there were too few studies (see Supplemental material).

Across 48 data points from 24 studies that compared NIS abundance or richness in urban and nonurban habitats, we find that NIS do indeed attain higher abundances and greater richness in more urbanized habitats (Fig. 5). This urbanization effect on NIS abundance appears strongest for invertebrates (insects and worms) and weakest for vertebrates (Fig. 5). It is important to note the small sample sizes for these comparisons.

Further, because there are so few studies, the main results of the meta-analysis could be influenced by biased publication of studies that report positive results. It is conceivable that the most problematic species or areas are prioritized for funding and for research. There are likely a number of databases or municipal-level habitat assessments or species inventories that provide information on NIS within urbanized areas, and such data would be useful for providing unbiased estimate of NIS abundance and richness.

Does NIS success in urban areas tell us about invasion and impact?

Although urban areas appear to provide opportunities for NIS to establish populations and persist where native species would otherwise be outcompeted or fail to thrive, this does not actually tell us about whether urban areas increase invasions per se. If NIS establish and thrive in urban habitats, it does not mean that they will necessarily spread beyond city centres or impact native biodiversity and ecosystem function. What evidence is there that NIS invasions are actually assisted by urbanization?

The novelty of the environmental conditions in urban areas, combined with the potential formation of new interactions between various NIS could set the stage for more NIS being successful over time-this is often referred to as invasional meltdown (Simberloff and Von Holle 1999). For example non-indigenous worms and shrubs facilitated one another's invasion 
(A) Population level

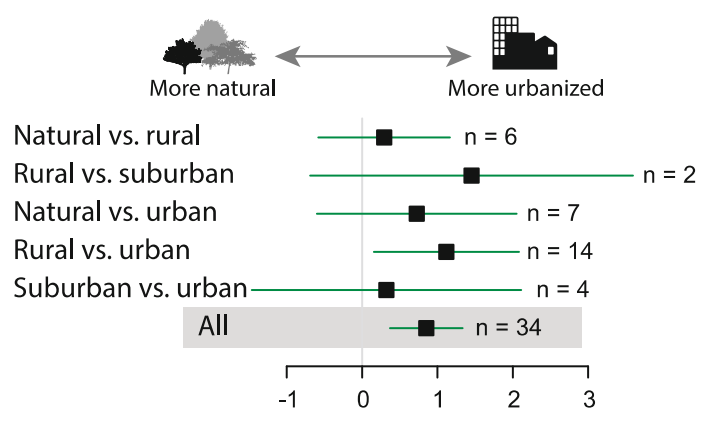

Invertebrate

Plant

Vertebrate

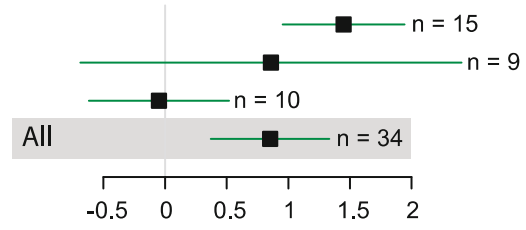

(B) Community level

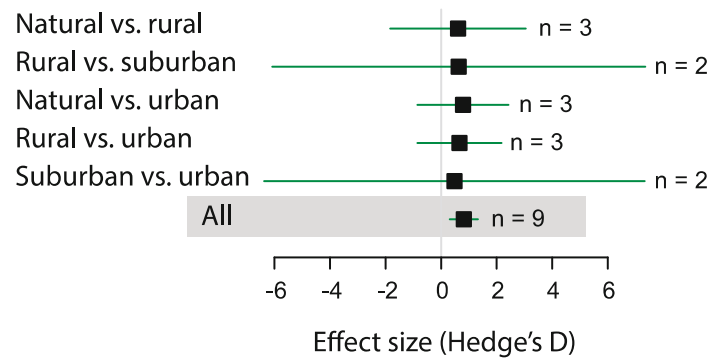

Fig. 5 The results of the meta-analysis comparing nonindigenous species (NIS) abundance (population level-A) and richness (community level-B) in urbanized habitats to more natural ones. Positive Hedge's D values correspond to greater abundance or richness values in more urbanized habitats

into Midwestern US urban woodlands (Heneghan et al. 2007). From this example, it is probable that either partner alone would have been unlikely to successfully invade, but the presence of both groups altered woodland ecology to their benefit, and these systems are unlikely to go back to native assemblages.

We know that independent of other factors, NIS most similar to native species compete the most and have the greatest impact on native abundance and diversity (Funk et al. 2008; Li et al. 2015; MacDougall et al. 2009; Pokorny et al. 2005), though this is not universally true since a distantly related NIS might possess a unique suite of traits that better equip them to compete for resources (Mayfield and Levine 2010; Strauss et al. 2006). Therefore, if urban areas provide opportunities for NIS to establish populations, just by random chance some will be closely related or ecologically similar to natives and if competition is an important mechanism they could potentially result in impacts on these similar natives. Moreover, the large diversity and population sizes of NIS in urban centres may serve as sources for invasions into nearby natural areas (Colautti et al. 2006; Lockwood et al. 2005; Moreira-Arce et al. 2015; Sullivan et al. 2005; Von Holle and Simberloff 2005). Thus, urban NIS should be carefully monitored and controlled because of the subsequent effects they may have outside of cities.

The broader impacts of NIS in urban areas can be complicated, and includes both positive and negative impacts (D'antonio and Meyerson 2002; Wan et al. 2009). If possible, native species should be supported and cultured to supply critical ecosystem services because NIS that supply these services may have other consequences that interfere with local management priorities. There has been a long and sometimes acrimonious debate about whether NIS impact native biodiversity (Davis et al. 2011a; Gurevitch and Padilla 2004; Sagoff 2005; Simberloff 2005, 2011), and further there are a number of publications (e.g., Pearce 2015; Zisenis 2015) that attempt to undermine the concern about potential negative impacts of NIS (see: Cadotte 2015). However, the available evidence suggests that plant invasions are the most important factor reducing local plant diversity globally (Vellend et al. 2013), and that NIS might benefit at the expense of natives within urban areas (Shochat et al. 2010). Thus, while NIS effects include positive, negative and neutral impacts, the observed or potential negative impacts on native diversity cannot be overlooked. However, it is worth noting that negative impacts from NIS might take a very long time to manifest (Downey and Richardson 2016), resulting in an underestimation of the negative impacts of invasion.

There might be quantifiable positive impacts associated with NIS in urban areas, but these positive consequences need to be evaluated against the full suite of NIS effects on other species and ecosystem functioning. Further, given the confounding effects of urbanization on ecological processes and NIS population dynamics, it is difficult to evaluate how NIS impact ecosystems as an independent influence (Rodewald et al. 2015). NIS might supplement or increase the delivery of ecosystem services, or replace the ecosystem service contributions formally provided 
by natives that have been extirpated in urban areas. NIS trees, for example, might increase the functional diversity of urban trees, which could enhance ecosystem services (Pataki et al. 2013; Potgieter et al. 2017). Even though NIS may be favoured in urban areas, they may replace native functions (Kendle and Rose 2000), for example, NIS trees and shrubs supporting native bird populations (Gray and van Heezik 2015). However, even in the case of supporting bird populations, it is unlikely that birds with differing ecological strategies will equally benefit from an abundant NIS and some species might still be adversely affected by urbanization or the NIS, or both (Schneider and Miller 2014). Studies have also concluded that NIS garden plants might benefit pollinators in urban habitats by supplying more consistent resources throughout the growing season (e.g., Salisbury et al. 2015; Tommasi et al. 2004). But again, not all pollinators will benefit equally. NIS floral resources are more likely to benefit generalist or non-indigenous pollinators at the expense of specialist and native pollinators (Bergerot et al. 2010; MacIvor et al. 2015). Thus, any general statements about the impacts of NIS in urban habitats need to be carefully evaluated against the full suite of cascading impacts, which require robust data.

\section{Well-designed studies are desperately needed}

The meta-analysis we completed makes one point abundantly clear-there are not enough studies that adequately assess the abundance and richness of NIS across gradients of urbanization. The main weakness is the gradient itself. The urban gradient is not synonymous with distance to urban centre, but rather should reflect the landscapes immediately surrounding sampled sites. The majority of the studies we examined had grouped sites into broad classes (e.g., urban, suburban, rural, etc.) that ignored among-site variation (but there are good examples to follow, e.g., Alston and Richardson 2006). The problem with this is that two sites categorized as, say, "suburban" might differ substantially in the composition of the area surrounding plots in terms of residential infrastructure, industrial activities, the number of size of roadways, the number of types of maintained parks, etc. More than just the influences of the physical structure of landscapes, the socio-economic spatial patterns in cities have important implications for biological diversity (Walker et al. 2009).
We would encourage investigators to instead quantify elements of the surrounding landscape (e.g., amount of impermeable surface, area under buildings, etc.) and create continuous measures of urbanization (e.g., Watts et al. 2015). Also, given that spaces studied in urban ecology research are unlikely to be randomly distributed (because of property zoning and the socio-economic history of urban development), there should be some statistical accounting of spatial autocorrelation. Given these criteria, we provide the following sequence of steps for analyzing urbanization effects on biodiversity:

1. Study sites can be selected a priori for specific reasons (e.g., all parks larger than 1 ha), randomly, or based on specific landscape features. If sites are selected according to either of the first two schemes, sample sizes should be large enough to provide sufficient variation in landscape structure.

2. GIS or other spatially explicit data should be obtained that includes some combination of environmental, human infrastructure, land use, socio-economic, NDVI, or other layers for the city being studied. Layers can be obtained from a number of governmental and non-governmental organizations. Sites could be selected based on the spatial distribution of these features.

3. The spatial features collated in step 2 should be quantified in at least two radii around sample sites-for example $500 \mathrm{~m}$ and $2000 \mathrm{~m}$ (e.g., Watts et al. 2015) to assess the influence of features over multiple spatial scales.

4. The spatial features should be combined with spatial distances between sites. The influence of these features on the variable of interest (e.g., NIS diversity) can be analyzed as individual predictors, for example using redundancy analysis (RDA), or combining features into composite multivariate measures from an ordination routine (e.g., 2-3 axes from a PCA). The latter approach is preferable to deal with covariance among spatial features.

5. Spatial distances could be analyzed as a feature in step 4, or to account for spatial autocorrelation in the variable of interest (Dale and Fortin 2014).

6. Linear or non-linear statistical models can then be used to assess the impact of urbanization on the variable of interest. 
Moving forward

While urban ecosystems do not fit our definitions of typical habitat types, applied ecologists and conservation biologists increasingly see the value in managing urban areas to maximize useable habitat for priority species (e.g., pollinators) or to increase the delivery of ecosystem services. NIS are undoubtedly an important component of these types of management priorities (Gaertner et al. 2016; Potgieter et al., this issue). However, NIS also present problems for other management actions. Thus, understanding how cities influence NIS, and vice versa, is critical for fully understanding their dynamics and developing evidence-based policy and management strategies.

In this review, we find evidence that NIS appear to attain higher abundances and diversity within urban habitats than surrounding rural and natural habitats. This opening for NIS invasion could mean that either urbanization provides unique habitat types that offer refuge and opportunity for NIS, like islands in an inhospitable sea, or that urban areas provide a beachhead for NIS to establish and further spread into other areas. There is evidence for both of these views, and future research would do well to attempt to distinguish between these outcomes.

Ultimately, for sound urban environment policy, we need to know what kinds of species use urban areas as a jumping off point for further invasion resulting in deleterious ecosystem impacts. Most of the research to-date has focused on broad habitat classes (e.g., urban vs. rural), but what is needed is a better understanding of how land-use at different spatial scales and human behaviour and preference drive NIS dynamics in urban areas (Pickett et al. 2016). We need detailed studies that incorporate fine scale land use, socio economic and human behavioural tendencies. Finally, researchers should evaluate how ongoing management regimes that are implemented without consideration of NIS (e.g., mowing, applying salt to roads in winter, etc.) actually impact NIS abundance and diversity.

Acknowledgements An early version of this paper was presented at the workshop on "non-native species in urban environments: Patterns, processes, impacts and challenges" that was hosted by the DST-NRF Centre of Excellence for Invasion Biology in Stellenbosch, South Africa, in November 2016. We are grateful to the helpful comments and suggestions from D. Richardson and two anonymous reviewers. We wish to acknowledge support from the Natural Sciences and Engineering Research Council of Canada (\#386,151), an Early Researcher Award from the Ontario Ministry of Research and Innovation (ER13-09-121), and the TD Chair of Urban Forest Conservation and Biology endowment, all awarded to MWC.

\section{References}

Airoldi L, Bulleri F (2011) Anthropogenic disturbance can determine the magnitude of opportunistic species responses on marine urban infrastructures. PLoS ONE 6:e22985

Akasaka M, Osawa T, Ikegami M (2015) The role of roads and urban area in occurrence of an ornamental invasive weed: a case of Rudbeckia laciniata L. Urban Ecosyst 18:1021-1030

Alberti M (2015) Eco-evolutionary dynamics in an urbanizing planet. Trends Ecol Evol 30:114-126

Allouche O, Kalyuzhny M, Moreno-Rueda G et al (2012) Areaheterogeneity tradeoff and the diversity of ecological communities. Proc Natl Acad Sci 109:17495-17500

Alston KP, Richardson DM (2006) The roles of habitat features, disturbance, and distance from putative source populations in structuring alien plant invasions at the urban/wildland interface on the Cape Peninsula, South Africa. Biol Conserv 132:183-198

Amarasekare P (2003) Competitive coexistence in spatially structured environments: a synthesis. Ecol Lett 6:1109-1122

Antunes P, Sanderson L (2013) The exotic invasive plant Vincetoxicum rossicum is a strong competitor even outside its current realized climatic temperature range. NeoBiota 16:1

Ariori CO (2014) Plant invasion along an urban-to-rural gradient. University of Connecticut, Connecticut, p 538

Aronson MF, La Sorte FA, Nilon CH et al (2014) A global analysis of the impacts of urbanization on bird and plant diversity reveals key anthropogenic drivers. In: Proceedings of the Royal Society of London B: Biological Sciences, p 20133330

Aronson MJ, Handel S, La Puma I et al (2015) Urbanization promotes non-native woody species and diverse plant assemblages in the New York metropolitan region. Urban Ecosyst 18:31-45

Barthell JF, Randall JM, Thorp RW et al (2001) Promotion of seed set in yellow star-thistle by honey bees: evidence of an invasive mutualism. Ecol Appl 11:1870-1883

Basnou C, Iguzquiza J, Pino J (2015) Examining the role of landscape structure and dynamics in alien plant invasion from urban Mediterranean coastal habitats. Landsc Urban Plan 136:156-164

Bergerot B, Fontaine B, Renard M et al (2010) Preferences for exotic flowers do not promote urban life in butterflies. Landsc Urban Plan 96:98-107

Bertness MD, Coverdale TC (2013) An invasive species facilitates the recovery of salt marsh ecosystems on Cape Cod. Ecology 94:1937-1943

Blair RB, Johnson EM (2008) Suburban habitats and their role for birds in the urban-rural habitat network: points of local invasion and extinction? Landsc Ecol 23:1157-1169 
Bongard C, Butler K, Fulthorpe R (2013) Investigation of fungal root colonizers of the invasive plant Vincetoxicum rossicum and co-occurring local native plants in a field and woodland area in Southern Ontario. Nat Conserv 4:55

Borgmann KL, Rodewald AD (2005) Forest restoration in urbanizing landscapes: interactions between land uses and exotic shrubs. Restor Ecol 13:334-340

Bowers MA, Breland B (1996) Foraging of gray squirrels on an urban-rural gradient: use of the GUD to assess anthropogenic impact. Ecol Appl 6:1135-1142

Brown JH (1984) On the relationship between abundance and distribution of species. Am Nat 124:255-279

Cadotte MW (2015) Taming the 'New Wild': tackling the good and the bad with invasive species. Biol Invasions 17:3067-3072

Cadotte MW, Lovett-Doust J (2001) Ecological and taxonomic differences between native and introduced plants of southwestern Ontario. Ecoscience 8:230-238

Cadotte MW, Tucker CM (2017) Should environmental filtering be abandoned? Trends Ecol Evol 32:429-437

Cappuccino N (2004) Allee effect in an invasive alien plant, pale swallow-wort Vincetoxicum rossicum (Asclepiadaceae). Oikos 106:3-8

Caswell H, Lensink R, Neubert MG (2003) Demography and dispersal: life table response experiments for invasion speed. Ecology 84:1968-1978

Chen X, Wang W, Liang H et al (2014) Dynamics of ruderal species diversity under the rapid urbanization over the past half century in Harbin, Northeast China. Urban Ecosyst $17: 455-472$

Chesson P (2000) Mechanisms of maintenance of species diversity. Annu Rev Ecol Syst 31:343-366

Chesson P, Huntly N (1997) The roles of harsh and fluctuating conditions in the dynamics of ecological communities. Am Nat 150:519-553

Chytrý M, Jarošík V, Pyšek P et al (2008) Separating habitat invasibility by alien plants from the actual level of invasion. Ecology 89:1541-1553

Colautti RI, MacIsaac HJ (2004) A neutral terminology to define 'invasive' species. Divers Distrib 10:135-141

Colautti RI, Grigorovich IA, MacIsaac HJ (2006) Propagule pressure: a null model for biological invasions. Biol Invasions 8:1023-1037

Connell JH, Slatyer RO (1977) Mechanisms of succession in natural communities and their role in community stability and organization. Am Nat 111:1119-1144

Corlett RT (2006) Figs (Ficus, Moraceae) in urban Hong Kong, South China. Biotropica 38:116-121

Cusack DF, Lee JK, McCleery TL et al (2015) Exotic grasses and nitrate enrichment alter soil carbon cycling along an urban-rural tropical forest gradient. Glob Change Biol 21:4481-4496

Dale MR, Fortin M-J (2014) Spatial analysis: a guide for ecologists. Cambridge University Press, Cambridge

D'antonio C, Meyerson LA (2002) Exotic plant species as problems and solutions in ecological restoration: a synthesis. Restor Ecol 10:703-713

Davis MA, Chew MK, Hobbs RJ et al (2011) Don't judge species on their origins. Nature 474:153-154

Dickson TL, Foster BL (2008) The relative importance of the species pool, productivity and disturbance in regulating grassland plant species richness: a field experiment. J Ecol 96:937-946

DiTommaso A, Lawlor FM, Darbyshire SJ (2005) The biology of invasive alien plants in Canada. 2. Cynanchum rossicum (Kleopow) Borhidi [= Vincetoxicum rossicum (Kleopow) Barbar.] and Cynanchum louiseae (L.) Kartesz \& Gandhi [= Vincetoxicum nigrum (L.) Moench]. Can J Plant Sci 85:243-263

Douglass C, Weston L, DiTommaso A (2009) Black and pale swallow-wort (Vincetoxicum nigrum and V. rossicum): the biology and ecology of two perennial, exotic and invasive vines. Management of invasive weeds. Springer, New York, pp 261-277

Downey PO, Richardson DM (2016) Alien plant invasions and native plant extinctions: a six-threshold framework. AoB Plants 8:plw047

Ernst C, Cappuccino N (2005) The effect of an invasive alien vine, Vincetoxicum rossicum (Asclepiadaceae), on arthropod populations in Ontario old fields. Biol Invasions 7:417-425

Ewel JJ, Putz FE (2004) A place for alien species in ecosystem restoration. Front Ecol Environ 2:354-360

Faeth SH, Warren PS, Shochat E et al (2005) Trophic dynamics in urban communities. Bioscience 55:399-407

Ferreira-Filho PJ, Piña-Rodrigues F, Silva J et al (2015) The exotic wasp Megastigmus transvaalensis (Hymenoptera: Torymidae): first record and damage on the Brazilian peppertree, Schinus terebinthifolius drupes, in São Paulo, Brazil. An Acad Bras Ciênc 87:2091-2095

Funk JL, Cleland EE, Suding KN et al (2008) Restoration through reassembly: plant traits and invasion resistance. Trends Ecol Evol 23:695-703

Gaertner M, Larson BMH, Irlich UM et al (2016) Managing invasive species in cities: a framework from Cape Town, South Africa. Landsc Urban Plan 151:1-9

Gavier-Pizarro GI, Radeloff VC, Stewart SI et al (2010) Housing is positively associated with invasive exotic plant species richness in New England, USA. Ecol Appl 20:1913-1925

Gering JC, Blair RB (1999) Predation on artificial bird nests along an urban gradient: predatory risk or relaxation in urban environments? Ecography 22:532-541

Golivets M (2014) Ecological and biological determination of invasion success of non-native plant species in urban woodlands with special regard to short-lived monocarps. Urban Ecosyst 17:291-303

Gray ER, van Heezik Y (2015) Exotic trees can sustain native birds in urban woodlands. Urban Ecosyst 19:315-329

Grime JP (1974) Vegetation classification by reference to strategies. Nature 250:26-31

Gurevitch J, Padilla DK (2004) Are invasive species a major cause of extinctions? Trends Ecol Evol 19:470-474

Helmus MR, Mahler DL, Losos JB (2014) Island biogeography of the Anthropocene. Nature 513:543-546

Heneghan L, Steffen J, Fagen K (2007) Interactions of an introduced shrub and introduced earthworms in an Illinois urban woodland: impact on leaf litter decomposition. Pedobiologia 50:543-551

Huston M, Smith T (1987) Plant succession: life history and competition. Am Nat 130:168-198

Ives CD, Hose GC, Nipperess DA et al (2011) Environmental and landscape factors influencing ant and plant diversity in 
suburban riparian corridors. Landsc Urban Plan 103:372-382

Keller RP, Cadotte MW, Sandiford G (2014) Invasive species in a globalized world. University of Chicago Press, Chicago

Kendle AD, Rose JE (2000) The aliens have landed! What are the justifcations for 'native only' policies in landscape plantings? Landsc Urban Plan 47:19-31

Knapp S, Dinsmore L, Fissore C et al (2012) Phylogenetic and functional characteristics of household yard floras and their changes along an urbanization gradient. Ecology 93:S83S98

Kowarik I (2011) Novel urban ecosystems, biodiversity, and conservation. Environ Pollut 159:1974-1983

Kraft NJB, Adler PB, Godoy O et al (2015) Community assembly, coexistence and the environmental filtering metaphor. Funct Ecol 29:592-599

Kricsfalusy VV, Miller GC (2008) Invasion and distribution of Cynanchum rossicum (Asclepiadaceae) in the Toronto region, Canada, with remarks on its taxonomy. Thaiszia $\mathbf{J}$ Bot 18:21-36

Ladd D, Cappuccino N (2005) A field study of seed dispersal and seedling performance in the invasive exotic vine Vincetoxicum rossicum. Botany 83:1181-1188

Lake JC, Leishman MR (2004) Invasion success of exotic in natural ecosystems: the role of disturbance, plant attributes and freedom from herbivores. Biol Conserv 117:215226

Lee TD, Perkins AL, Campbell AS et al (2015) Incipient invasion of urban and forest habitats in New Hampshire, USA, by the nonnative tree, Kalopanax septemlobus. Invasive Plant Sci Manag 8:111-121

Levine JM, Vila M, D'Antonio CM et al (2003) Mechanisms underlying the impacts of exotic plant invasions. Proc R Soc Lond Ser B Biol Sci 270:775-781

Li S, Cadotte MW, Meiners SJ et al (2015) The effects of phylogenetic relatedness on invasion success and impact: deconstructing Darwin's naturalisation conundrum. Ecol Lett 18:1285-1292

Lockwood JL, Cassey P, Blackburn T (2005) The role of propagule pressure in explaining species invasions. Trends Ecol Evol 20:223-228

Lonsdale WM (1999) Global patterns of plant invasions and the concept of invasibility. Ecology 80:1522-1536

Loyd KAT, Hernandez SM, Carroll JP et al (2013) Quantifying free-roaming domestic cat predation using animal-borne video cameras. Biol Conserv 160:183-189

Ma C, Li S-P, Pu Z et al (2016) Different effects of invadernative phylogenetic relatedness on invasion success and impact: a meta-analysis of Darwin's naturalization hypothesis. Proc R Soc B Biol Sci 283:20160663

MacDougall AS, Gilbert B, Levine JM (2009) Plant invasions and the niche. J Ecol 97:609-615

MacIvor JS, Ruttan A, Salehi B (2015) Exotics on exotics: pollen analysis of urban bees visiting Sedum on a green roof. Urban Ecosyst 18:419-430

Mayfield MM, Levine JM (2010) Opposing effects of competitive exclusion on the phylogenetic structure of communities. Ecol Lett 13:1085-1093

McCune J, Vellend M (2015) Using plant traits to predict the sensitivity of colonizations and extirpations to landscape context. Oecologia 178:511-524
McDonnell M, Hahs A (2013) The future of urban biodiversity research: moving beyond the 'low-hanging fruit'. Urban Ecosyst 16:397-409

Milbrath LR (2008) Growth and reproduction of invasive Vincetoxicum rossicum and $V$. nigrum under artificial defoliation and different light environments. Botany $86: 1279-1290$

Moles AT, Flores-Moreno H, Bonser SP et al (2012) Invasions: the trail behind, the path ahead, and a test of a disturbing idea. J Ecol 100:116-127

Moreira-Arce D, de la Barrera F, Bustamante RO (2015) Distance to suburban/wildland border interacts with habitat type for structuring exotic plant communities in a natural area surrounding a metropolitan area in central Chile. Plant Ecol Divers 8:363-370

Moro MF, Castro ASF (2015) A check list of plant species in the urban forestry of Fortaleza, Brazil: where are the native species in the country of megadiversity? Urban Ecosyst 18:47-71

Naeem S, Knops JMH, Tilman D et al (2000) Plant diversity increases resistance to invasion in the absence of covarying extrinsic factors. Oikos 91:97-108

Nielsen AB, van den Bosch M, Maruthaveeran S et al (2014) Species richness in urban parks and its drivers: a review of empirical evidence. Urban Ecosyst 17:305-327

Parker IM (1997) Pollinator limitation of Cytisus scoparius (Scotch broom), an invasive exotic shrub. Ecology 78:1457-1470

Pataki DE, McCarthy HR, Gillespie T et al (2013) A trait-based ecology of the Los Angeles urban forest. Ecosphere 4:art72

Pearce F (2015) The new wild—why invasive species will be nature's salvation. Beacon Press, Boston

Peterson AT (2003) Predicting the geography of species' invasions via ecological niche modeling. Q Rev Biol 78:419-433

Petren K, Case TJ (1998) Habitat structure determines competition intensity and invasion success in gecko lizards. Proc Natl Acad Sci USA 95:11739-11744

Pheloung PC, Williams PA, Halloy SR (1999) A weed risk assessment model for use as a biosecurity tool evaluating plant introductions. J Environ Manag 57:239-251

Pickett STA, McDonnell MJ (1989) Changing perspectives in community dynamics: a theory of successional forces. Trends Ecol Evol 4:241-245

Pickett ST, Cadenasso ML, Grove JM et al (2008) Urban ecological systems: linking terrestrial ecological, physical, and socioeconomic components of metropolitan areas. Urban Ecol. Springer, pp 99-122

Pickett STA, Meiners SJ, Cadenasso ML (2011) Domain and propositions of succession theory. In: Scheiner SM, Willig MR (eds) The theory of ecology. University of Chicago Press, Chicago, pp 185-216

Pickett ST, Cadenasso ML, Childers DL et al (2016) Evolution and future of urban ecological science: ecology in, of, and for the city. Ecosyst Health Sustain 2:e01229

Pokorny ML, Sheley RL, Zabinski CA et al (2005) Plant functional group diversity as a mechanism for invasion resistance. Restor Ecol 13:448-459

Potgieter LJ, Gaertner M, Kueffer C, Larson BMH, Livingstone S, O'Farrell, P, Richardson DM (2017) Alien plants as mediators of ecosystem services and disservices in urban 
systems: a global review. Biol Invasions. doi:10.1007/ s10530-017-1589-8

Prange S, Gehrt SD, Wiggers EP (2003) Demographic factors contributing to high raccoon densities in urban landscapes. J Wildl Manag 67:324-333

Pyšek A, PyšEk P, Jarošík V et al (2003) Diversity of native and alien plant species on rubbish dumps: effects of dump age, environmental factors and toxicity. Divers Distrib 9:177-189

Pyšek P, Jarošík V, Hulme PE et al (2010) Disentangling the role of environmental and human pressures on biological invasions across Europe. Proc Natl Acad Sci 107:12157-12162

Pyšek P, Jarošík V, Hulme PE et al (2012) A global assessment of invasive plant impacts on resident species, communities and ecosystems: the interaction of impact measures, invading species' traits and environment. Glob Change Biol 18:1725-1737

Pyšek P, Blackburn TM, García-Berthou E et al (2017) Displacement and local extinction of native and endemic species. Impact of biological invasions on ecosystem services. Springer, New York, pp 157-175

Ricotta C, La Sorte FA, Pysek P et al (2009) Phyloecology of urban alien floras. J Ecol 97:1243-1251

Riley SP, Busteed GT, Kats LB et al (2005) Effects of urbanization on the distribution and abundance of amphibians and invasive species in southern California streams. Conserv Biol 19:1894-1907

Rodewald AD, Rohr RP, Fortuna MA et al (2015) Does removal of invasives restore ecological networks? An experimental approach. Biol Invasions 17:2139-2146

Sagoff M (2005) Do non-native species threaten the natural environment? J Agric Environ Ethics 18:215-236

Salisbury A, Armitage J, Bostock H et al (2015) Enhancing gardens as habitats for flower-visiting aerial insects (pollinators): should we plant native or exotic species? J Appl Ecol 52:1156-1164

Schneider SC, Miller JR (2014) Response of avian communities to invasive vegetation in urban forest fragments. Condor 116:459-471

Schwartz MW, Thorne JH, Viers JH (2006) Biotic homogenization of the California flora in urban and urbanizing regions. Biol Conserv 127:282-291

Shea K, Chesson P (2002) Community ecology theory as a framework for biological invasions. Trends Ecol Evol 17:170-176

Shochat E, Lerman SB, Anderies JM et al (2010) Invasion, competition, and biodiversity loss in urban ecosystems. Bioscience 60:199-208

Simberloff D (2005) Non-native species do threaten the natural environment! J Agric Environ Ethics 18:595-607

Simberloff D (2011) Non-natives: 141 scientists object. Nature 475:36

Simberloff D, Von Holle B (1999) Positive interactions of nonindigenous species: invasional meltdown? Biol Invasions 1:21-32
Smith RM, Thompson K, Hodgson JG et al (2006) Urban domestic gardens (IX): composition and richness of the vascular plant flora, and implications for native biodiversity. Biol Conserv 129:312-322

Soh MCK, Sodhi NS, Lim SLH (2006) High sensitivity of montane bird communities to habitat disturbance in Peninsular Malaysia. Biol Conserv 129:149-166

Strauss SY, Webb CO, Salamin N (2006) Exotic taxa less related to native species are more invasive. Proc Natl Acad Sci USA 103:5841-5845

Sullivan JJ, Timmins SM, Williams PA (2005) Movement of exotic plants into coastal native forests from gardens in northern New Zealand. N Z J Ecol 29:1-10

Tommasi D, Miro A, Higo HA et al (2004) Bee diversity and abundance in an urban setting. Can Entomol 136:851-869

Vellend M, Baeten L, Myers-Smith IH et al (2013) Global metaanalysis reveals no net change in local-scale plant biodiversity over time. Proc Natl Acad Sci 110:19456-19459

Von der Lippe M, Kowarik I (2007) Long-distance dispersal of plants by vehicles as a driver of plant invasions. Conserv Biol 21:986-996

Von Holle B, Simberloff D (2005) Ecological resistance to biological invasion overwhelmed by propagule pressure. Ecology 86:3212-3218

Walker JS, Grimm NB, Briggs JM et al (2009) Effects of urbanization on plant species diversity in central Arizona. Front Ecol Environ 7:465-470

Wan S, Qin P, Liu J et al (2009) The positive and negative effects of exotic Spartina alterniflora in China. Ecol Eng 35:444-452

Watts AG, Lukasik VM, Fortin M-J et al (2015) Urbanization, grassland, and diet influence coyote (Canis latrans) parasitism structure. EcoHealth 12:645-659

Wei A, Chow-Fraser P (2006) Synergistic impact of water level fluctuation and invasion of Glyceria on Typha in a freshwater marsh of Lake Ontario. Aquat Bot 84:63-69

Wilby RL, Perry GLW (2006) Climate change, biodiversity and the urban environment: a critical review based on London, UK. Prog Phys Geogr 30:73-98

Williams NSG, Schwartz MW, Vesk PA et al (2009) A conceptual framework for predicting the effects of urban environments on floras. J Ecol 97:4-9

Wu SH, Sun HT, Teng YC et al (2010) Patterns of plant invasions in China: taxonomic, biogeographic, climatic approaches and anthropogenic effects. Biol Invasions 12:2179-2206

Yasui S-LE (2016) Intraspecific variation and phenotypic plasticity in the invasive vine Vincetoxicum rossicum. University of Toronto, Toronto

Zisenis M (2015) Alien plant species: a real fear for urban ecosystems in Europe? Urban Ecosyst 18:355-370 